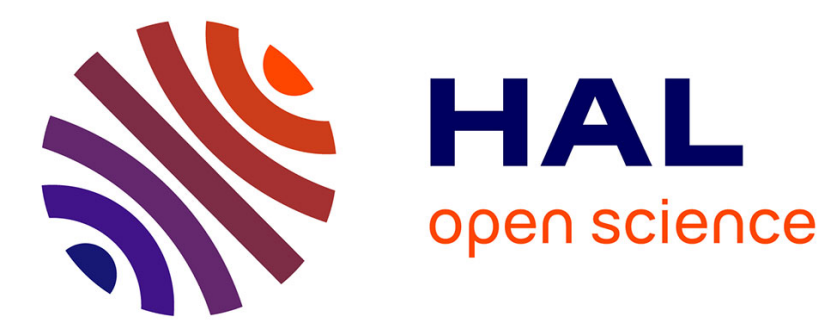

\title{
Achievement goals and perceived ability predict investment in learning a sport task
}

François Cury, Stuart K. Biddle, Philippe Sarrazin, Jean-Pierre Famose

\section{To cite this version:}

François Cury, Stuart K. Biddle, Philippe Sarrazin, Jean-Pierre Famose. Achievement goals and perceived ability predict investment in learning a sport task. British Journal of Educational Psychology, 1997, 67 (3), pp.293-309. 10.1111/j.2044-8279.1997.tb01245.x . hal-00387226

\section{HAL Id: hal-00387226 https://hal.science/hal-00387226}

Submitted on 25 May 2009

HAL is a multi-disciplinary open access archive for the deposit and dissemination of scientific research documents, whether they are published or not. The documents may come from teaching and research institutions in France or abroad, or from public or private research centers.
L'archive ouverte pluridisciplinaire HAL, est destinée au dépôt et à la diffusion de documents scientifiques de niveau recherche, publiés ou non, émanant des établissements d'enseignement et de recherche français ou étrangers, des laboratoires publics ou privés. 
Achievement goals and perceived ability predict investment in learning a sport task

\author{
Francois Cury* \\ Laboratoire de recherche en STAPS, University of Paris XI-Orsay, France
}

Stuart Biddle ${ }^{\star}$

School of Education, University of Exerer

Philippe Sarrazin

Laboratoire d'etudes et recherches surl 'offre sportive (YEROS), University of Grenoble I, France

Jean Pierre Famose

Laboratoire de recherche en STAPS, University of Paris XI-Orsay, France

Background. Contemporary views on motivation suggest that expectancy-value and
social-cognitive perspectives can shed light ton the important issue of student motivation. a sport task. Two studies investigated whether investment in learning is affected by

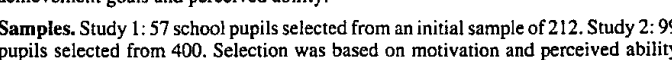
scores from questionnaires. Pupils were aged $13-15$ years and attended schools in scores from ques
northem France.

Methods. In Study 1 pupils prepared themselves for a sport task with a five-minute period of training. Study 2 pupils prepared themselves with a five-minute period of training after prior failure.

Results. Study 1 showed that those who were ego-involved with a low perceived a high perceived ability, or those task-involved regardless of their perceived ability. Ego-involved pupils used an attributional bias to minimise the effect of effort on

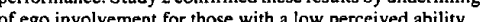

Conclusions. School pupils with high ego involvement in a sport task and low
perceived ability show motivational deficits which manifest themselves in less time spent on practising a task, A social-cognitive and expectancy-value perspective appears to be valid for the study of motivational processes in school physical

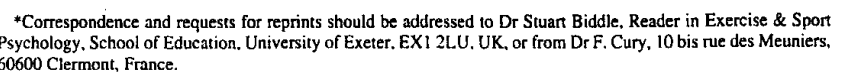

Contemporary perspectives of achievement motivation have defined as one of their principal objectives the explanation and prediction of human behaviour in educational contexts (e.g.. 1989). This research is based on a social cognitive perspective which gives achievert goals a central place in the initition and regulation of behaviours and is referred to as 'goals theory' (Weiner, 1990) or the 'achievement goal approach' (Roberts, 1992). Here the individual is considered as an intentional organism, directed by a goal, and who behaves in a rational manner. For this theory, in an achievement context such as an academic situation, of central interest is the demonstration of competence. This can be done in two main ways which are associared with two distinct motivational goals. On the one hand, the individual can demonstrate ability by establishing superiority over others. In this case, the feeling of personal competence is established by a normative comparison process, and by using socially referenced evaluation criteria. For the individual it is about revealing a higher ability than his or her peers or avoiding the display of low competence. Success or failure is not with those of others. Behaviour motivated in this way is described as exhibitin eno involvemenr (Nicholls, 1984a, 1989), or the pursuit of a performance or ego goal (Ames, 1984a. Dweck, 1986; Nicholls, 1989).

Alternatively, one can establish competence by displaying personal progress. The feeling of competence is then based on a process of temporal comparison and self referenced criteria. The goal of the individual is to improve ability and to progress towards task mastery. This refers to task involvement (Nicholls, 1984a, 1989), a learning goal (Dweck. 1986), or a mastery or lask goal (Ames, 1984a, Duda, 1992).

Although the first sudies of achievement goals were in classroom contexts, the existence and the independence of these two achievement goals have also been demonstrated in the Roberts \& Balague, 1991), and in school physical education (Biddle, Cury, Goudas, Sarrazin, Famose \& Durand, 1995).

As supported by Duda (1992), in an achievement situation the preferred goal of the individual (i.e., ego involvement vs. task involvement) depends on situational factors, and on a personal predisposition with regard to one of the two goals (Ames, 1992b; Maehr, 1984; Nicholls, 1989), and these two factors can intervene jointly in behaviours and attitudes (Cury, Biddle, Famose, Goudes, Durand \& Sarrazin. 1996). The predispositional aspect of individual achievenent is the result of a socialisation process which tends to lead the child towards particular motivational orientations (i.e., task orientation vs. ego orientation), possibly in relation to culthral values passed on by the family and school. In this case we takk about individual motivational orientation, it being relatively stable and long lasting, and which information from the immediate situational concept (Ames \& Archer, 1988; Biddle er al 1995; Cury et al 1996) tends to focus the learner on one goal over another. In particular. competitive situations, situations which are presented as tests, or which value public selfconsciousness by imposing performance salience in front of an audience or video camera, contribute to the development of ego involvement. On the other hand, in a context centred on learning, progress, and which proposes tasks with a difficully level adapted to each individual, task involvement is more likely (Ames, 1992a, 1992b; Butler, 1992; Nicholls,
$1984 b, 1989$ ). 
This theoretical framework supports the idea of a rational link between achievement goals and the learning behaviours of individuals, whether in the academic or sporting fiel (Ames, 1992a, Duda, 1992; Dweck, 1986; Famose, Sarrazin \& Cury, 1995; Heyman Dweck, 1992; Nicholls, 1989; Roberts, 1992). According to achievement goal theory, the choice of a lask or dif iculty level (Nicholls, 1984b; Sarrazin, Famose \& Cury, 1995), the Rudisill 1990) and (Duda, Smart \& Tappe, 1989), perseverance (Elliott \& Dweck, 1988; are behaviours which are influenced by the interaction between the god pursued by the individual (task involvement vs ego involvement) and the perception of personal com by the This general hypothesis has its foundation in two general theories of motivation.

An expectancy-value theory of motivation

The expectancy-value approach describes a psychological process which drives the individua either to invest or not to invest in a situation depending on the attractiveness and the accessibility of the task. An individual engages in a given situation in relation to the nature of investich and cognitive operations which allow him or her to evaluate the feasibility of the project. On the one hand, they evaluate what the task will bring by assigning to it be satisfied. On the other hand the individual recognent will allow motivational goals to success expectation), taking into considertion its difficulty and their own pereced the The combination of the attractiveness and accessibility which they atribute to the task subsequently induces a level of identifiable investment in learning behaviours such as effor or perseverance. Consequently, when task involved, an individual invests in the situation if they think that this will allow them to progress and to master the task. If they judge tha high effort is necessary to improve competence or to resolve the given problem, they allocate a substantial amount of energy to accomplish the task. Conversely, energy will be ow the the a high investmen would be in vain. Faced wh that the which is perceived as too easy or too difficult (in the the problem seems to be of an optimal level of difficulty they con

give the opportunity to confirm their superiority or to avoid revealing themselves as incapable in the eyes of their peers, and will try to avoid any effort which will reveal low competence. In these conditions, the level of normative difficulty is significant for deciding the degree of investment (Nicholls, 1984b). To fail on a normatively average task reveals a low ability, which is not the case if the task is perceived as normatively very difficult. Consequently, hose who perceive hemselves as incompetent will avoid trying on tasks with normatively average difficulty, and devote energy to easy tasks, since these represent a limited failur risk, or very difficult asks, because, in this case, the failure is not necessarily due to a lack of ability. An individual who has great confidence in their own ability invests in average on easy tasks becuss they are aninate withor mone. The and effort will be limited and on very difficult tasks, as failure appears to be possible in spite of maximum effort.

The attribution approach

The attributional model is supportive of the predictive value of goal theory on learming

behaviours by focusing on the way that the pupil interprets information from the task and infers particular reasons for the results of his or her actions. One of the most importan theoretical contributions of this approach to the understanding of learning behaviours is in the capacity of the theory to demonstrate the links between atrributions for performance and preferred goal pursued by the individual.

Numerous authors defend the idea of relationships between the nature of accomplishmen (i.e., task involvement vs. ego involvement) and attributions (Ames, 1992a; Ames \& Archer, 1988; Butler, 1987, 1992, Ellon \& Dweck, 1988; Jagacinski \& Nicholls, 1984, 1987, Nicholls, 1989. 1992). Generally, the studies indicate that when an individual is ego involved, they are more likely to attribute pefformance to abihy, and more so if the actual result incompetent in normatively difficult tasks. A failure, therefore, confirms one's fears and the individual attributes this result to a lack of ability.

On the other hand, an unexpected success should be attributed to chance. If the individual has confidence, they will attribute their success to their high level of competence, and find an external cause (e.g., bad luck) to explain a failure. In attribution theory, ability is considered to be an internal cause and one that is stable and uncontrollable (Graham, 1991; Weiner, 1986). Consequently, when the individual atributes a resulf to a stable cause like ability, they consider that in an identical situation the same causes should produce the same effects. Therefore, alubuling a fillue to a stable cause (low abily) should conthibute to reduced future expectations of success. Convinced of their incapacity to change, the person Effort is the principal casse put forward to exp a

a result when task involved. When hactors which they think are capable of modifying future expectation of success depends on change in the strategy used to solve the problem), or which the environment can give to the person (e.g., the help and advice of a teacher or friend). Confronted with failure the individual should persist in the aask by increasing effort or by searching for supplementary information to change the strategy. Encountering success should reinforce convictions concerning the virtue of effort and the individual should be more persistent.

The attributional approach allows us to explain ego involved protective strategies which influence subsequent behaviours. An ego involved individual who anticipales the subsequent result an be competence (Covington, 1985: Covington \& Omelich, 1979; Pyszczynci \& Orembers 1983). They can also falsify the objective reasons for performance (attributional bias) by allocating low effort to performance. In this way, an individual who has failed can suggest lack of effort to avoid the association of failure with low ability, and one who has succeeded can increase their own value by minimising their investment in effort (Harris \& Snyder. 1986: Thill, 1993; Tice, 1991).

The purpose of this research, therefore, is to test the predictive value of achievement goals theory on the investment in the learning of a sport task. To our knowledge. few studies have tried to show the influence of achievement goals and perceived ability on the considered a behavioul indicar of perseverence (Mesterent ing; a learning activity is 
Rudisill, 1990), and volitional effort (Jagacinski \& Nicholls, 1984, 1990), and constitutes particularly important estimate of learning motivation (Ames, 1992a, 1992b; Dweck, 1986 reference to the theoretical frameworks discussed, we investigated whether task involved school pupils demonstrate stronger investment in learning compared to those who are ego involved and with low perceived ability

\section{Study}

The main objective of this study was to test the predictive value of achievement goals, is combination with perceived ability, on the time in which the individual prepares for a test.
referred to as 'investment in learning'.

\section{Metho}

The study was structured according to a $2 \times 2$ design of achievement goal (task involvement, ego involvement) $x$ perceived ability (high, low). Dependent variables consisted of the time devoted to prepare for the test (investment in learning), the perception of situationally

induced motivational goals,
given to task accomplishment

Sample

Fifty-seven French males, aged 13-15 years (mean=14.1, SD=0.81) were selected from 212 college pupils according to two questionnaires appraising their dispositional motivational profile (1.e., task orientation and ego orientation), and their perceived competence level in groups:

1. a high ego orientation, low task orientation and low perceived ability group $(N=13)$ 2. a high ego orientation, low task orientation and high perceived ability group $(N=15)$ 4. a low ego orientation high task orientation and high perceived ability group $(N=14)$

To form these groups, we used percentile scores for each subscale of the motivational orientation questionnaire. Pupils were classified as high in one orientation when they were situated in the highest third part of the distribution, and low when they were situated in the was greater than 6 the scale midpoint, while low ability was indicted by a score of less than or equal to 6 .

\section{Experimental task}

The pupils were requested to perform a ball dribble exercise in basketball. The course was made up of a series of obstacles that the performer had to negotiate while dribbling baskeball. The test consisted of a timed atempt and was preceded by a five-minute period for training. Participaion was voluntary, but no pupil declined. Informed consent was

\section{Measures}

the Perception of Sarrazin \& Famose (1996). This is a French version of the Perception of Success Questionnaire of Roberts \& Ballague (1991). The questionnaire invites the participant to recall moments during which they experienced a strong feeling of success in sport. Six items represent task orientation (e.g., 'I progress after having made a big effort'), and six items represent an ego orientation (e.g., 'I am the best'). Answers are given on five-poin scales anchored by 'don't agree at all' (I) and 'agree completely' (5). In the present study, the alpha intemal consisto coeffient (Cronbach, 1951) of boh the task orentation (a) from prior research (Duda

Perceived basketball ability. The Specific Perceived Ability Questionnaire (SPAQ). developed by Famose, Sarrazin \& Cury (1994), was used to assess perceived ability level in a particular sporting activity (in this case basketball). The instrument comprises four item (e.g. 'When you play basketball and you compare yourself to most friends of your age, you feel .... The answers are indicated on an 11-point scale anchored by 'very bad' (1) and 'very good' (II). In previous research conducted on teenagers, the SPAQ has shown good construct validity, internal consistency and test-retest reliability. Evidence relative concunent vallity, in predichive valdity of the questiontire hyve also been established (Famose et al., 1995; Sarrazin et al., 1995). In this study, the internal consistency was high (alpha=.86).

the rest went in learning. To assess this construct, the time taken by pupils to prepare for left the pupil on his own for five minutes with the instruction that there, was a possibility train on the course in order to prepare for the test if the pupil so desired. During the period, the pupil was observed secretly from a room adjoining the test room, and the time spent on the circuit was recorded. At the end of the five-minute period, the experimeter reappeared and continued with the experimental procedure as announced at the outset of the experiment.

Situationally-induced motivational goal, atrributed effort, and importance given to task success. After testing, pupils rated two statements symbolising a lask involved context (i.e. In your opinion, we can say that the purpose of this experience is to test a learning method this experiencis is to , and an ego involved concal (i.e., 'In your opinion, the purpose of dribble technical level'), Ratings were made on a scale from 'don't agree at all' to 'agree completely.

In addition, pupils rated two statements concerning effort attributed to his performance (i.e., 'In your view, to prepare for this test, how much effort did you make?'), rated on scale from 'very little' to 'very much', and the value which the pupil assigns to the accomplishment of the course (i.e., For you, to succeed in this course is something that is .. This was rated on a scale from 'Title importance to "very important'. The pupis answered whse questions by placing a vertical line between the two extremities of a $30 \mathrm{~cm}$ 
the individual to position himself in relation to the question asked. Before each passage pupil was allowed practice on a series of examples in the presence of the experimenter.

Procedure

The pupils were tested individually and the experiment took place as follows: Circuit presentation and induction to the motivational context. In the first phase, the experimenter presented orally, and through an active demonstration, the basketball dribbling circuit. The pupil was also placed in a condition conforming to his motivational profile to guarantee the viability of the goal (i.e., a pupil from the high ego orientation/low lask orientation group was placed in a context inducing ego involvement and is named 'ego involvement-low perceived ability' or 'ego involvement-high perceived ability'. A pupil from the low ego orientation/high task orientation group was placed in a context inducing task involvement and is named 'task involvement-low perceived ability' or 'task involvementhigh perceived ability. In the context inducing ego involvement, the pupili is told that this level of dribling from the iine une on the circit The sted objective was to locate the 30 best dribblers within a group of 60 selected pupils among the school sample. The eenaser was filmed on video, and told at the end of the test series that all the participants could view the names of those selected and discarded.

In a context inducing task involvement, we indicated to the pupil that the purpose of the experience was to test the teaching quality of a circuit for use in the learming of basketball at school. The aim of the individual was to check whether he could quickly improve his dribbling. First test and goal to reach. The pupil made his first timed attempt to ensure his understanding of the task. Time taken was noied by the experimenter but no feedback was given. Then, the experimenter suggested that the pupil should reach a goal. In the context inducing ego involvement, the experimenter announced, with reference to an established schedule reling to tornagers' $p$ prof if the selected group of pupils of his own ase. In the context inducing a task involvement the experimenter told the pupil that significant progress is obtained if he achieves a time of 2:30, which represented an improvement of 20 per cent compared to his established time during pre-test.

Measurement of perception of the situational goal, value atributed to the task, and investment in learning. The pupil was called upon to evaluate his perception of the goal induced by the context and the value which he attached to the task. Next, he was allowed five minutes to prepare for the test during which he was observed secretly, as outhed earlier.

Feedback and measurement of atribured efforl. After practice. the pupil was given information on his performance. The feedback formulation was identical for both conditions.

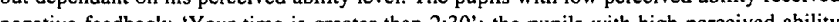
received positive feedback: 'Your time is less than 2:30'.

areful consideration was given to ethical issues in the conduct of this study. Unebrusive observation was deemed safe and acceptable given that the activities observed were normal activities used on a daily basis in physical education lessons. Secondly, and in accordance with the British Psychological Socjety's Code of Conduct. observation was deemed acceptable given that the pupils could expect, during the normal school day, to be observed by visitors as well as other members of the school community.

However, given the sensitive nature of unobtrusive observation, debriefing took place at a post-study meeting with the pupils, teachers and parents. Full information about the
nature of the study was given and questions were taken freely

\section{Results}

Data analysis revealed unequal variance between the experimental groups concerning the importance given to the task (Hartley $F \max =8.74, p<.004$ ), the perception of ego involvement induced by the context (Hartley $F \max =6.71 p<.01)$, and the perception of task involvement induced by the context (Hartley $F \max =11.14, p<.0005$ ). This was not the case for the time devoted to the rest preparation, neither for the effort attributed. Kruskal-Wallis ANOVA by ranks showed a significant effect of induced goal on the ego involvement perception induced by the context $(H(1, N=57)=38.89), p<.0001)$, and on the task involvement perception
induced by the context $(H(1, N=57)=29.62), p<0001)$. The pupils confronted with a context induced by the context $(H(1, N=57)=29.62), p<.0001)$. The pupils confronted with a context
inducing an ego involvement perceived this motivational dimension more strongly $(N=28, \mathrm{~S}$ inducing an ego involvement perceived this motivational dimension more strongly $(N=28, \mathrm{~S}$
of ranks $=1201.5)$ than the pupils placed in a context inducing a task involvernent $(N=29, \mathrm{~S}$ of ranks $=451.5$. The pupils confronted with a context inducing a task involvement perceived this motivational dimension more strongly $(N=29, S$ of ranks=1180.5) than the pupils placed in a context inducing an ego involvement $(N=28, S$ of ranks=472.5). These results confirm the validity of the motivation induction.

Effects on the importance attached to the task

Kruskal-Wallis ANOVA by ranks did not show any significant effect $(\mathrm{H}(1, N=57)=1.77)$, $p<.182$ ) for the goal on the importance effect was shown for perceived ability $(\mathrm{H}(1, N=57)=23.758), p<.00001)$. Consequently, pupils who perceived themselves to be incompetent attached less value to the task $(N=28, S$ of ranks $=508.5)$ than those who had high perceived ability $(N=29$, $S$ of ranks $=1144.5)$. Mann-Witney U test showed: (a) that the ego involved-low perceived ability group attached (b) that the task involved-low perceived ability group had lower task value then the task involved-high pereived bility group $(p<034)$ and the epo involved high perceived ability group $(p<002)$; (c) that the task involved-high perceived ability and the ego involved-high perceived ability groups valued the tasks equally.

\section{Effects on investment in learning and attributed effort}

A MANOVA conducted on time taken for practice (investment in learning) and attributed effort revealed a significant multivariate effect of goal $(F(2,52)=20.06$, lambda $=.514$, $p<.00001)$, and perceived abilhy $(F(2,52)=11.19$, lambda $=.699, p<.00009)$, and an interaction becween the wo independent variables (IVS) ( $(2,52)=9.94$, lambda $=.868, p<.025)$. An ANOVA on investment in learning confirmed the previous results by highlighting: (a) a math ect for goal $(F(1,53)=26.30, p<.00001)$ and for perceived ablitity $(F(1,53)=20.24$, Newman-Keuls preparing for the test than the other three groups (see Table 1). 
Table 1. Means $(M)$ and standard deviations (SD) for investment in learning and effort attributions in Study 1

\begin{tabular}{l|cccc|cccc}
\hline & \multicolumn{4}{|c|}{ Ego involvement } & \multicolumn{4}{c}{ Task involvement } \\
\hline & \multicolumn{2}{|c|}{$\begin{array}{l}\text { Low perceived } \\
\text { ability }(N=13)\end{array}$} & $\begin{array}{l}\text { High perceived } \\
\text { ability }(N=15)\end{array}$ & \multicolumn{2}{c}{$\begin{array}{l}\text { Low perceived } \\
\text { ability }(N=15)\end{array}$} & \multicolumn{2}{c}{$\begin{array}{c}\text { High perceived } \\
\text { ability }(N=14)\end{array}$} \\
\hline Measures & $M$ & SD & $M$ & SD & $M$ & SD & $M$ & SD \\
\hline $\begin{array}{l}\text { Investment } \\
\text { in learning } \\
\text { (secs) }\end{array}$ & 155.07 & 49.92 & 230.73 & 46.22 & 237.93 & 44.11 & 265.14 & 36.16 \\
$\begin{array}{l}\text { Effort } \\
\text { attributions }\end{array}$ & 13.12 & 5.02 & 17.03 & 3.76 & 20.43 & 4.96 & 19.96 & 4.69 \\
\hline
\end{tabular}

ANOVA on attributed effort showed a main effect for goal $(F(1.53)=17.48, p<.0001$ but not for perceived ability $(F(1,53)=1.979 p<.165)$, and there was no significant interactio $(F(1.53)=3.20, p>.05)$

The motivational goal, therefore, influenced investment in learning and the effort assigned to prepare for the test. Task involved pupils reported more effort and attributed their perceived ability invested less in test preparation than high perceived ability pupils. The origin of the variation in investment in learming is more related to the specific position of the ego involvement-low perceived ability group in relation with the three other groups (see Table 1). As far as attributed effort is concerned, the source of the variation is more generally due to the goal $(M=15.21(N=28)$, for the ego involvement condition, and $M=20.2$ $(N=29)$, for the task involvement condition).

Relationship between investment in learning and attributions

al bias from a simple linear regressio effort over the different groups.

(a) for ego involvement-low perceived ability and ego involvement-high perceived ability these pupils, the higher theen investment in learning and attributed effort is negative. For subsequently to the result.

(b) in the task involvement-low perceived ability group, the more the pupils spent time in preparing for their test the more they related their performance to the importance of effort.

Table 2. Linear regressions between investment in learning and effort attributions in Study 1

\begin{tabular}{lllll}
\hline Goal/perceived ability & $N$ & $r$ & $r$ & $F, p<$ \\
\hline ego/low & 13 & -.657 & .432 & 8.38 .02 \\
egolhigh & 15 & -535 & .286 & 5.21 .04 \\
lasklow & 15 & .557 & .310 & 5.05 \\
laskh/high & 14 & .110 & .012 & 2.45 .03 \\
\hline
\end{tabular}

\section{Discussion}

Overall, the results agree with the theoretical framework developed earlier and show the predictive value of achievement goals in investment in learning and on attributional bias. The study points out that the status given to the test determines the investment the pupil puts into its preparation. Facing a normatively average task, an ego invoived pupil with a low perceived ability anticipates demonstrating incompetence. Effectively, failure on a task at such a level of difficulty confirms low ability, the more so if the effort expended to obtain the result is high (Jagacinski \& Nicholls, 1984, 1987). Therefore, the pupil is likely to attempt to disengage himself emotionally from a paingll situation by discedif task, and putting in less effort than pupis in other groups.

Pupils from the ego involvement-high ability group anticipated their demonstration of them to thin their motiviont gosis. Consequenty, they pu in effort to acheve their ims. The pupils who were takk involved howeve, tried hard whatever their level of perceived ability. The goal prescribed by the experimenter was perceived positively. consequently the pupil could look forward to progress and mastery of the task independently of his initial perceived competence. Also, the task was better valued by pupils high in perceived ability compared to those who had less confidence in their abilities.

The results show that attributed effort depends principally on the nature of the achievement. Whatever their level of perceived ability, the task involved pupils spent greater effort in preparing for the test than ego involved pupils. This result is in agreement with one of the condamental constructs of achievement goals heory which argues for a strig 1992. Duda 1992. Heyme feedback in accordance with their perceived ability level reinforced the two groups of $e$ involved pupils in their forecast and helped autribute the result to ability rather than effort The regression analysis between investment in learning and attributed effort suggests that the pupils use effort attributions for different ends. The pupils who were ego involved tended to minimise the consequences of their investment. This mechanism is extensively described by self-worth theory but not yet verified in the motor learning domain (Harris \& Snyder, 1986; Thill, 1993; Tice, 1991). These pupils may distort their answers by attributing their poor performance to low effort. In this way. failure is assigned to a lack of effort and hence may act as a form of self-esteem protection. Altematively, he more energy devoled to prepanng for the rest, the more the pupls who are ask involed atrbute their result thar a it is cort. In this The the leaning prose ego involved and who use this to avoid being deprecated in the eyes of others.

Study 2

The purpose of this study was to confirm the predictive value of achievement goals specifically for the perseverence of pupils after failure. This should allow us to study the mediating role played by the pupirs success expectalion when confronted with fallte.

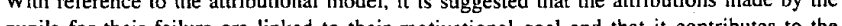
pupils for their fallure are linked to their mo sugional goll and ing 
Method

In parallel with Study 1, this study involves a goal (task involvement, ego involvement) $x$ perceived (high, low) design. The dependent variables consist of the perception of the motivational goal induced by the context, success expectation formulated after a prior failure. and the time devoted to prepare for a test (investment in learning) following test failure.

Sample

Male French school pupils $(N=99)$, aged 13-15 years (mean $=13.8, S D=0.78$ ), were selected from 400 pupils according to their motivational profile and their perceived ability level in basketball. $B$ using a simlar procedure as hat outlined in Sludy 1 , we creared four groups: a high ego orientatio hich perceived ability low percived ability group $(N=23)$; a high ego onentation/low task and bility grop $(N-25)$; 5); and a low ego orientation/high task orientation and high perceived ability Task

The basketball dribbling task was identical to that used in Study 1. Participation was voluntary, but no pupil declined. Informed consent was obtained from the pupils and, since testing took place in normal school time, their teachers as well.

Measures

Motivational orientation, perceived ability in basketball and perception of the motivational goal Study 1 . For the PSSQ These variables were measured by tools and procedures as outlined fo

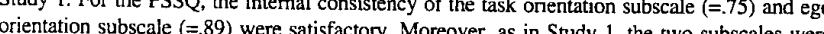
independent $(r=08, p>05)$. The SPAQ also had good inem Success expectation. Pupis determined their success expectation (ie "in) the foilowed procedures identical to those in Study 1.

Procedure

The selected pupils were tested individually as follows:

Circuit presentation and motivational climate induction. The circuit presentation and the context which induced an experience was to locat the 50 hes dran, we told the pupils that the purpose of the the school population. In the context inducing task involvepent ith pupis selected from the importance of good concentration and doing one's best.

Negative feedback and goal to reach. The pupils completed a first timed attempt to ensure that the task was understood. Following the first test, the experimenter commented negatively on the pupil's performance then proposed a temporary goal for him to reach. In context inducing ego involvement, the pupil was told: 'You have not produced a very good time compared to the other pupils who have performed. Then the pupil is told that with he nee to an established schle reshing to the pefformance of teenagers in other schools, heve ants to stand a good chance of rating
304 Francois Cury, Stuart Biddle, Philippe Sarrazin and Jean Pierre Famose

In the situation inducing task involvement, the pupil was told: 'You have not produced a good time, you have not concentrated enough on the course.' Then he is told that significant
progress can be obtained if he produces a time of $2: 30$, which represents a 20 per cent improvement compared to his performance established during the pretest.

Measurement of the perception of the goal induced by the context, success expectation, and investment in learning. The pupil was requested to rate his perception of the task context and success expectation. Then he was allowed five minutes to prepare for Test 2 during which he was observed secretly, as described in Study

Tethe ethical and debriefing procedures wer used as documented in Study 1.

\section{Results}

The initial analyses showed similar variances between the four comparison groups for all dependent variables. A $2 \times 2$ (goal $\times$ perceived ability) MANOVA conducted on all dependent variables revealed multivariate main effects for goal $(F(5,91)=86.13$, lambda $=207, p<.00001)$, and perceived ability $(F(5,91)=10.155$, lambda $=694, p<.00001)$, as well as an interaction between the two IVs $(F(5,9)=6.519$, lambda $=.779, p<.0002)$. Pupils placed in a contex inducing ego involvement $(M=24.52, \mathrm{SD}=4.38)$ perceived the situation as more ego involving $(F(1,95)=221.26, p<.00001)$ han pupils induced into task involvement $(M=11.12, \mathrm{SD}=5.14)$, Similarly, the pupils placed in a context inducing task involvement $(M=22.2, S D=5.38$

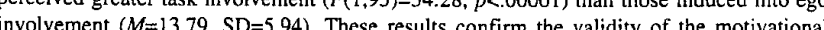
induction, which was also observed in Study 1 .

Effects on success expectation

The results showed an interaction $(F(1,95)=9.26, p<.003)$ between goals and perceived ability. Post-hoc Newman-Keuls test showed that ego involved pupils with low perceived ability expressed lower success expechlins than the olher groups (see Table 3). In addition, the pupils high in perceived ability expressed higher success expectations $(M=23.28, \mathrm{SD}=4.77$ $F(1,95)=21.76, p<.00001)$ than pupils low in perceived ability $(M=18.43, \mathrm{SD}=6.22)$

Table 3. Means $(M)$ and standard deviations (SD) for investment in learning and success expectations after failure (Study 2)

\begin{tabular}{l|cccc|cccc}
\hline & \multicolumn{4}{|c|}{ Ego involvement } & \multicolumn{4}{c}{ Task involvement } \\
\hline & \multicolumn{2}{|c|}{$\begin{array}{l}\text { Low perceived } \\
\text { ability }(N=25)\end{array}$} & $\begin{array}{l}\text { High perceived } \\
\text { ability }\end{array}(N=25)$ & \multicolumn{2}{c}{$\begin{array}{l}\text { Low perceived } \\
\text { ability }(N=23)\end{array}$} & $\begin{array}{l}\text { High perceived } \\
\text { ability }(N=26)\end{array}$ \\
\hline Measures & $M$ & SD & $M$ & SD & $M$ & SD & $M$ & SD \\
\hline $\begin{array}{l}\text { Investment } \\
\text { in learning } \\
\text { (secs) }\end{array}$ & 147.78 & 65.64 & 236.65 & 56.86 & 237.32 & 50.99 & 254.08 & 48.69 \\
$\begin{array}{l}\text { Success } \\
\text { expectation }\end{array}$ & 15.85 & 5.06 & 24.02 & 4.53 & 20.80 & 6.34 & 22.52 & 4.98 \\
\hline
\end{tabular}


Effects on investment in learnin

A significant interaction $(F(1.95)=10.34, p<.002)$ between shown on the amount of time invested in learning, Post-hoc Newman-Keuls test revealed that the ego involvement-low perceived ability group spent less time in the task after receiving a negative comment than the other groups (see Table 3). Pupils placed in a context inducing task involvement persisted longer $(M=245.7, S D=50.06 ; F(1,9 S)=22.76$, $p<.00001)$ than pupils placed in a context inducing ego involvement $(M=194.94, \mathrm{SD}=75.28)$. Similarly, puphls high in pecived abilly (ME245.

A structural equation modelling analysis

To test the links between the dependent variables, and to specify likely causal pathways, a structural equation modelling analysis was conducted. This tests a hypothesised model against the data observed. Three paths and one mediation were specified. A negative path from ego involvement to expectation, a positive path from task involvement to expectation, 列 research (see correlation matrix in Table 4).

Table 4. Intercorrelations between perceived ego involvement, perceived task involvement. success expectations, and investment in learning (Study 2).

\begin{tabular}{|c|c|c|c|}
\hline & 1 & 2 & 3 \\
\hline $\begin{array}{l}\text { 1. perceived ego involvement } \\
\text { 2. perceived task involvement } \\
\text { 3. success expectations } \\
\text { 4. investment in leaming }\end{array}$ & $\begin{array}{l}-.585^{* * * *} \\
-.439 * * * \\
-593 * * *\end{array}$ & $\begin{array}{l}.329 * * * \\
.283 *\end{array}$ & $.649 * * *$ \\
\hline
\end{tabular}

$* *_{p<01}^{* * p<001 * * * p<0001}$

The structural equation modelling analysis was performed using LISREL VIII (Joreskog \& Sorbom, 1993) and showed that the specified model (model l) did not fit the observed data particularly well. The chi ${ }^{2}$ was highly significant, hus rejecting the null hypothesis, and shows a difference between real observations and the proposed model. Additional indices confirm this observation: chi'/d.f. ratio is much greater than 2 and the Adjusted

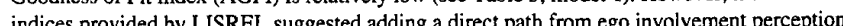

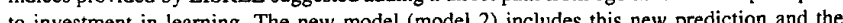
indices of fit are substantially improved (see Table 5). Model 2 appears to be a good fit 10 the observed data (see Figure 1).

Table 5. Indices of fit for the structural equation models tested in Study 2.

\begin{tabular}{lll}
\hline Indices of fit & Model 1 & Model 2 \\
\hline Chi squared & 13.76 & 1.09 \\
d.f. & 2.001 & 1 \\
P. & .30 \\
Chiz/d.f. ratio & 6.88 & .09 \\
GFI & .94 & .99 \\
AGFI & .69 & .95 \\
RMSR & .078 & .019 \\
\hline
\end{tabular}

Figure 1. Structural equation model for Model 2 (Study 2). The dotted path is not significant; all others are significant $(p<.01)$

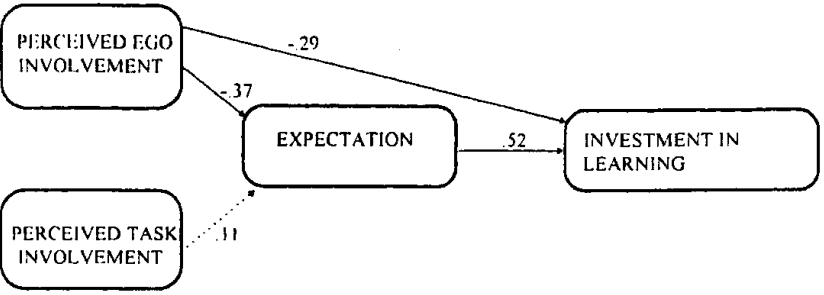

Examination of the model reveals the predictive strength of ego involvement. It negatively predicts success expectation and investment in learning. Consequently, after failure, the more a pupil perceives the situation to be ego involving the less he thinks he has a chance of success and the less he perseveres at the test. However, task involvement does not induce any significant effect, rejecting our hypothesis that it would have a positive influence. In addition, expectation predicts investrent in learning. That is, a pupil who thinks hat task success is likely, or possible, perseveres longer in preparing for his test. Also, the perception of ego involvement infuences investment in learning through success expectation. That is, gives himself to perform well, the less perseverance is observed in test preparation.

\section{Discussion}

The results generally conform to our assumptions. The pupils high in ego involvement and low in perceived abilty had lower success expectations than the other groups, and persevered less on the task. This confirms Study $l$ and underlines the psychological weakness of pupils placed in such a motivational state. The present study also highlights the reactions of pupils

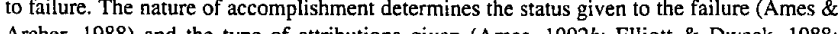
Archer, 1988) and the lype of attributions given (Ames, 1992b; Elliott \& Dweck. 1988; group attributed their failure to ability and gave themselves litrle chance to solve a task of normatively average difficulty. This seemed to urge them to quit a training situation early. Conversely, an initial failure did not affect the pupils with high ego involvement-high perceived ability who attribute this preliminary result to external causes (Nicholls, 1989). In consequence, they remained engaged in the task and prepared actively for the test.

The pupils who were task involved had a very different interpretation of their encountered failure. The nature of the feedback seemed to reinforce attributing their failure to a lack of effort and concentalion. These pupls were confroned with a lask conmensurate with their competence. consequenly, whatever heir inithal perceived ability level, the pupils from these two groups formed high success expectations, hence they remained engaged in mastering 
The interpretation of the structural equation model confirms these results. In particular the results clearly show the predictive value of the perception of an ego involvement induced by the context. This variable negatively predicts the expectation of success and investment in practising the task. In agreement with the theoretical frameworks discussed, failure induces a deteriorating action on learning investment when ego involvement is perceived as strong. This can be explained in who ways. First, his goal tends to reduce sacess $x$ pis is likely to be de to atributing their foilure io a srable cause, such as low ability (Graham, 1991: Weiner, 1986). Second, ego involvement perception reduces the investment in learning of the pupils by a direct causal path. This observation confirms earlier data which suggests that the perception of ego involvement induced by the context is positively related to attitudes and behaviours maladaptive for learning (Ames \& Archer. 1988; Biddle et al., 1995; Cury et al.. 1996). For some pupils, in particular for those ego involved with law perceived ability, an inithal fallure associated with a new normative evaluation of ability may create negative emotion for the individual, thus reducing his investment in the task.

Finally, the busts point out the predictive value of success expectation for subsequent perseverance. The more an individual thinks of succeeding, the more he perseveres at the 1988: Nicholls, 1989) and expectancy-value theories.

\section{General discussion and conclusion}

The results from the two studies are consistent with the theoretical frameworks used and confirm the hypotheses concerning investrent in learing. The data confim that pupils who are ego involved and have low confidence in their capacities engage a negative attitude and resist practice. The preferential goal pursued by the individual, and the success expectations he has for himself, induces investment in the task and influences progress.

A cognitive approach to motivation allows us to examine psychological mechanisms which provide this theory wh high explandorys and prediche vare. As "llion \& Deck (1988) commands, decision rules, and inference rules, and hence, with different cognitive, affective and behavioural consequences. Each goal, in a sense, creates and organises its own world each evoking different thoughts and emotions and calling forth different behaviours' (p. 11). When an individual is ego involved, the attractiveness and accessibility of a task are dependent on perceived ability and on the normative difficulty of the task. The causes of performance are then attributed more often to ability (Graham, 1991). The perception of success requires the demonstration of superior ability, either by obtaining a beter result than others or by establishing an identical result with lower effort (Covington. 1985, Jagacinski \& Nicholls, 1984). Conversely, failure intervenes when performance confirm. an inferior ability compared to others or by an identical result to others in spite of greater impornat consequences for the individul's self-worth (Covington \& Omelich, 1979) and investment over time on the task.

Conversely, when the individual is task involved, the attractiveness and accessibility of the task depends only on the subjective probability of success, and a good performance is generally explained by effort. The individual perceives his performance as a success or a fallure if he observes or does not observe progress and mastery of the task due to the effort exerted. This motivational state is not dependent on perceived ability and induces long-term investment in the task. As Ames (1992b) says: 'Central to a mastery goal is a belief that efort and outcome covary, and this is the attributional beli The data reported by the two studies support the val

the validity of achievement goals theory for investment in the learning of a sport task, and bring ecological validity to this achievement motivation perspective.

\section{References}

Ames, C. (1984a). Achievement attributions and self--nstructions under competitive and individualistic goal siructures. Acoumal of Ed

analysis. In R. Ames \& C. Ames (Eds). Research on Morivation in E: a cognitive-motivational Motivarion, (pp. 177-208). New York: Academic Press.

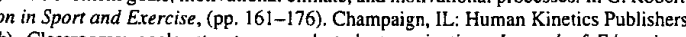
Ames, C. (1992b). Classrooms: goals, structures, and student motivation. Journal of Educationa Ames, C. \& Archer, I. (1988). Achievement goals in the classroom: student's learning strategies an

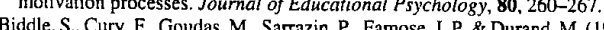

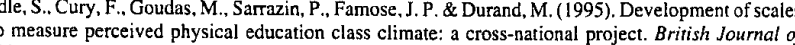
Educational Psychology, 65, 341-358.

feedback conditions on Psychology, 79, 474-482.

, R. (1992). What young people want to know when: effects of mastery and ability goals on intere in different kinds of social comparisons. Journal of Personality and Social Psychology, 62, 934-943,
Butter, R. (1993). Effects of task and ego-achieverment goals on information seeking during engagement. Journal of Personality and Social Psychology, 65, 18-31.

Congton, M. V. (1985). Straggie thinking and fear of fallure. In J. Segal, S. Chipman \& R. Glaser (Ed), Covington, M. V. \& Omelich, C. L. (1979). Effort the double-edged sword in school acherevenen. Journal of Educational Psychology, 71, 169-182.

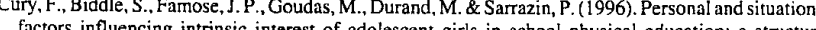
equation modelling analysis. Educational Psychology, 16,305-315. Duda, J. L. (1992). Motivation in sport settings: a goal perspective approach. In G. Roberts (Ed) Mativa.

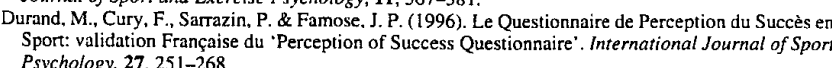

Dweck, C. S. (1986). Motivational process affecting learning. American Psychologiss, 41, 1040-1048.
Elliott. E. S. \& Dweck. C. S. (1988). Goals: an approach to motivation and achievement, Journal Personality and Social Psychology, 54. 5-12.

sportive Document interne Cury, F. (1994). Un Questionnaire dै' Habileté Perçue Spécifique à l'activiv 
Famose, J. P.. Sarrazin, P. \& Cury, F. (1995). Apprentissage moteur et burs d'accomplissement en éducation physique et sportive. In $J$. Bertsch 20 . Le Graham, S. (1991). A review of attribution theory in achievement contexts. Educational Psychology Harris, R. N. \& S Snyder, C. R. (1986). The role of uncertain self-esteem in self-handicapping. Journal of Personality and Social Psychology, 51, 451-158. Achievement goals and intrinsic mor their role in adaptive motivation. Motivation and Emotion, 16.231-247.
Jagacinski, C. M. \& Nicholls, J. G. (1984). Conceptions of ability and related affects in task involvement and ego involvement. Journal of Educcational Psychology. 76. $909-919$.

Jgacinski, C. M. \& Nicholls,J.J.G. (1987). Competence and affectin task involvement and ego involvement: Jagacinski, C. M. \& Nicholls, J. G. (1990). Reading effort to protect perceived ability: 'they'd do it but Joreskog. K. G. \& Sortom, D (1993) Lisrel 8. Structural Equation Modeling with the SIMPUIS Conmand Language. Hillsdale, NJ: Erlbaum

Maehr, M.L. (1984). Meaning and motivation: toward a theory of personal investment. In R. Ames \& C. New York. Academic Press. Ans Eillur, A. \& Hom, H.L. L. (1990). Influence of extrinsic and ego incentive value on persistence after failure and continuing motivation. Journal of Educational Psychology, 82, 539-545.

cholls, J. G. (1984a). Conceptions of ability and achievement motivation. In R. Ames \& C. Ames (Eds), Research on Motivation in Education: $V$ al Rehils,J.G. (1984b). Achievement motivation: conceptions of ability, pupilive experience, task choice, Nicholls, J. G. (1989). The Comparative Ethos and Democratic Education. Cambridge, MA: Harvard University Press.
Nicholls, J. G. (1992). The general and the specific in the development and expression of achievement
motivation. In G. Robers (Ed), Motivation in Sport and Exercise, (pp. 31-56). Champaign, IL: Human

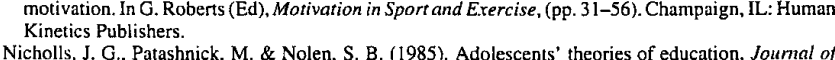

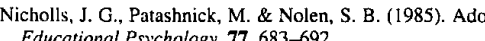
Educational Psychology, 77, 683-692.
Pyszczynski, T. \& Greenberg J. (1983). Determinants of reduction in intended effort as a strategy for coping with annipate

convergence. In G. C.

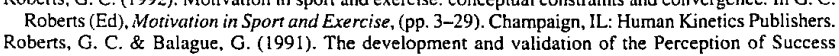

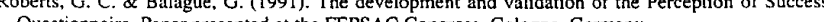
Questionnaire. Paper presented at the FEPSAC Congress, Cologne, Germany.
Rudisill, M. E. (1990). The influence of various achieverentr goal orientations on children's perceived competence, expectations, persistence for three motor tasks. Journal of Human Movement Studies, 19. $231-249$
Surrazin, $\mathrm{P}$.

Sarrazin, P., Famose, J. P. \& Cury, F. (1995). But motivationnel, habileté perç̧ue et sélection du niveau

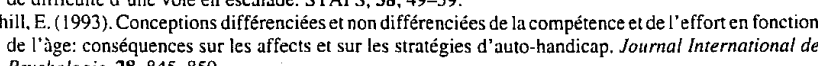
Tice, D. M. (1991). Estreem protection or enhancement? Self-handicapping motives and atrributions differ

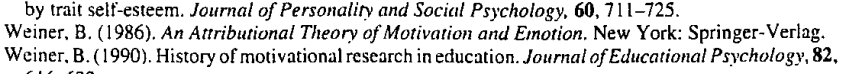
616-622.

(Manuscript received 21 Auguss 1996: final version 27 November 1996) 